\title{
Pelatihan Manajemen Bimbingan Belajar Online Bagi Jemaat dan Aktivis Dewasa Muda di Gereja Bethel Indonesia, Tangerang
}

\author{
Yonathan Winardi, Siane Indriani, Wiputra Cendana, Robert Soesanto \\ Universitas Pelita Harapan \\ Universitas Pelita Harapan \\ Universitas Pelita Harapan \\ Universitas Pelita Harapan \\ yonathan.winardi@uph.edu, siane.indriani@uph.edu, wiputra.cendana@uph.edu, robert.soesanto@uph.edu
}

\begin{abstract}
Abstrak
Pandemi CoVid19 yang berkelanjutan dengan adanya pemberlakuan Pembatasan Kegiatan Masyarakat (PPKM) mikro yang berkepanjangan menyebabkan bertambahnya pengangguran, pembatalan pembelajaran tatap muka bagi siswa/i sekolah dasar, dan sulitnya mempertahankan keberlangsungan serta kualitas bimbingan belajar (bimbel) di Tangerang, Banten. Hal-hal tersebut dialami jemaat dan aktivis gereja usia produktif di salah satu Gereja Bethel Indonesia yang berlokasi di kota Tangerang, baik yang belum berkeluarga, maupun yang sudah berkeluarga di mana para ibu rumah tangga sangat memerlukan kecakapan mendampingi anak-anak mereka di rumah ketika home-based learning (HBL). Oleh karena itu, tujuan dari pelatihan manajemen bimbingan belajar yang juga mencakup pedagogi mengajar Matematika dasar serta Bahasa Inggris adalah untuk memampukan peserta membuka dan mempertahankan bimbel online, membuka lapangan pekerjaan bagi mereka yang terdampak pandemi dan memampukan para ibu rumah tangga mendampingi putra-putri mereka di tahun ajaran baru 2021/2022. Setelah melakukan needs analysis melalui e-form yang dibagikan dan mengetahui bahwa belum pernah diadakan pelatihan sejenis di masa lalu di gereja tersebut, para dosen pengajar tidak hanya akan membawakan materi manajemen pendidikan dan pedagogi pembelajaran Matematika serta Bahasa Inggris dalam pelatihan sinkronus sebanyak 4 pertemuan, tetapi juga memberikan pendampingan asinkronus selama 3 minggu kepada 21 peserta melalui media Zoom dan Whatsapp. Hasil kegiatan pelatihan dan pendampingan telah memampukan sebagian peserta untuk membuka bimbel baru dan mendampingi anak-anak mereka belajar Matematika dan Bahasa Inggris di rumah menggunakan sumber-sumber belajar online yang otentik.
\end{abstract}

Kata Kunci : Bimbingan belajar online, manajemen, pedagogi Matematika dan Bahasa Inggris

\section{PENDAHULUAN}

Dengan kondisi pandemi yang berkepanjangan dan diberlakukannya Pembatasan Kegiatan Masyarakat (PPKM), hal ini berdampak pada hampir seluruh aspek kehidupan masyarakat.
Bertambahnya pengangguran adalah salah satu dampak yang dimaksudkan, ditambah lagi pada sektor pendidikan, dimana terjadi pembatalan dan ketidakpastian pembelajaran tatap muka bagi siswa/i sekolah dasar, dan sulitnya mempertahankan keberlangsungan serta kualitas bimbingan belajar 
(bimbel) di Tangerang, Banten. Hal-hal tersebut dialami oleh jemaat dan aktivis gereja usia produktif, baik yang belum berkeluarga, maupun yang sudah berkeluarga dimana para ibu rumah tangga sangat memerlukan kecakapan mendampingi anak-anak mereka di rumah ketika home-based learning (HBL). Dengan adanya analisa situasi dan masalah yang dialami jemaat GBI rayon 3 yang berpotensi sebagai mitra PKM yang telah dipaparkan di atas, maka diperlukan perencanaan yang serius untuk dapat membantu para baik para individu yang terbeban untuk mendampingi siswa belajar melalui wadah bimbingan belajar online dan juga bagi orangtua yang memiliki peran yang sangat penting untuk mendukung pembelajaran anak-anak dari rumah. Jelas terdapat kebutuhan akan kegiatan PKM yang dapat menjadi sarana untuk memperlengkapi, saling berbagi, dan forum diskusi antara guru bimbel, orangtua dan juga dengan para pengajar dari UPH yang membagikan metode pembelajaran dan sumber-sumber belajar online yang dapat diterapkan dalam proses pendampingan anak-anak dari rumah atau tempat bimbel online. Tim PKM memastikan bahwa pelatihan sejenis belum pernah dilakukan ataupun dialami oleh para calon peserta PKM, sehingga pelatihan yang diusulkan menjadi sebuah ide inovasi bagi kemajuan jemaat dewasa muda di gereja yang dituju.

Tugas siswa yang paling utama adalah belajar dan memahami/menemukan konsep yang sedang dipelajari. (Hanifah, Isrok'atun, \& Sujana, 2018). Dengan kondisi di mana anak-anak belajar secara online seperti sekarang ini, maka diperlukan kemampuan guru bimbel online atau orangtua untuk dapat memilih sumber-sumber belajar online yang sesuai dengan level kemampuan anak-anak dan yang efektif. Selain itu, bagaimana sumber-sumber belajar tersebut nantinya dapat digunakan sebagai sarana yang dapat mempererat interaksi dan hubungan antar anak dan orangtua, dan juga anak-anak didik dengan para guru di bimbel online. Sebagaimana yang diketahui bahwa sumber belajar yang menekankan interaksi merupakan salah satu faktor yang terbilang esensial karena mampu memperkaya proses belajar siswa (Apsari et al., 2020). Hal ini dilatarbelakangi oleh sebuah penyebab berupa hilangnya momen interaksi secara langsung, khususnya antara pendidik dan siswa selaku subjek yang dididik (Manurung et al., 2020). Mau tidak mau, pembelajaran di masa pandemik harus memanfaatkan sumber belajar yang memanfaatkan ICT sebagai basisnya (Kerimbayev et al., 2020). Namun, tentunya pemanfaatan ICT sebagai dasar penyusunan sumber belajar bukanlah merupakan hal yang terbilang atau tidak ada tantangan. Temuan pada studi yang dilakukan oleh (Muhazir \& Retnawati, 2020) mengemukakan bahwa kemampuan pedagogi berbasis teknologi yang dimiliki oleh guru masih sangat rendah.

Tantangan pun tidak hanya berpusat pada pribadi seorang guru. Ketidakmampuan guru untuk menjangkau siswa selama pembelajaran berlangsung, membutuhkan peran dari orang tua di rumah (Abuhammad, 2020). Dalam hal ini, orangtua memiliki peran tambahan sebagai guru kedua bagi anak dalam belajar di rumah. mendampingi anak ketika belajar adalah sesuatu yang sangat penting bagi anak yaitu dapat membangun kedekatan antara orang tua dengan anak (Iftitah \& Anawaty, 2020). Guru bimbel dan orangtua juga memerlukan hikmat dari Tuhan, agar dapat mendampingi anak-anak dan memantau perkembangan belajar anak-anak melalui aplikasi-aplikasi online yang dapat digunakan untuk meningkatkan keterlibatan aktif mereka dan natinya juga meningkatkan kemandirian dalam proses pembelajaran. Teachers need to carefully consider and purposefully plan and facilitate student learning in support of the development of self-regulation in an online environment (Lock, Easton, \& Kessey, 2017).

Teknologi seharusnya membuat guru maupun orangtua untuk dapat berpikir lebih dalam bagaiamana mereka dapat menggunakannya utk mengembangkan proses berpikir anak, hal ini tentunya kemampuan untuk menghubungkan materi yang dipelajari anak dari sumber-sumber online tersebut dengan kebutuhan mereka di masa yang akan datang. Improving the lives of our students is, after all, one of the motivators for why we teach (Jacobsen \& Lock, 2004). Apalagi dengan banyaknya variasi aplikasi yang dapat digunakan anak untuk mendapatkan informasi secara cepat dengan hanya membuka laptop mereka dan terkoneksi dengan internet, maka guru maupun orangtua zaman sekarang tidak dapat lagi merancang proses pembelajaran seperti bagaiamana proses belajar mereka terdahulu.

Selain pelatihan dapat berarti sebagai 
kegiatan edukatif untuk mengubah perilaku SDM ssat ini menjadi perilaku yang lebih baik, pelatihan juga berhubungan dengan pengembangan pengetahuan dan kemampuan yang akan digunakan segera (Nazar dkk, 2019). Yusuf dan Putra (2019) menambahkan bahwa program pendidikan dan pelatihan harus direncanakan dengan prosedur yang baik dan benar agar dapat berjalan secara efektif dan efisien mencapai tujuan. Oleh karena itu, disusunlah tim PKM yang melibatkan 4 dosen lintas program studi serta 1 mahasiswi tingkat 3 dari program studi Pendidikan Bahasa Inggris UPH. Melalui kegiatan pelatihan di PKM ini, diharapkan dapat memberikan gambaran bagi praktisi bimbel online dan orangtua yang mendampingi proses belajar anak-anaknya dari rumah untuk dapat memanfaatkan sumber-sumber belajar online yang menarik untuk mengajarkan prinsip-prinsip hidup dari Firman Tuhan yang akan berguna untuk kehidupan anak-anak di masa yang akan datang. Melalui kegiatan PKM ini, juga diharapkan adanya komunikasi dua arah antara pengelola bimbel online yang sudah berjalan maupun orangtua yang mendampingi anak-anaknya di rumah, sehingga terus ada diskusi yang bekelanjutan jika terdapat kendala-kendala terkait dengan proses pembelajaran maupun pendampingan kepada anakanak yang diajar. Dengan demikian, keunikan dari PKM ini adalah integrasi wawasan alkitabiah di dalam setiap materi yang disampaikan oleh setiap pembicara dan juga pendampingan yang intensif selama 2 bulan penuh melalui grup media sosial.

\section{METODE}

Terdapat enam langkah utama yang dilakukan dalam pelatihan pembukaan dan manajemen bimbel selama bulan Agustus dan September 2021. Pelatihan yang baik tentulah dimulai dari analisa kebutuhan pelatihan yang tajam serta komprehensif yang berujung pada materi serta penyampaian materi yang efektif. Peserta pelatihan dapat mengalami apa yang disebut effective learning sehingga terdapat hasil pelatihan yang diharapkan dan bermutu. Berikut adalah paparan dari keenam langkah yang dilakukan dalam pelatihan.

Yang pertama adalah analisa kebutuhan (training needs analysis) lewat kuisioner online https://forms.office.com/r/Ewst7GeZHr dan koordinasi dengan mitra pelatihan yaitu ketua departemen Dewasa Muda salah satu Gereja Bethel Indonesia dimana mitra menyiapkan sosialisasi kepada calon peserta pelatihan mengenai materi, peraturan, dan tata laksana pelatihan pembukaan dan manajemen bimbel. Mitra juga kemudian menyiapkan poster/flyer sebagai berikut

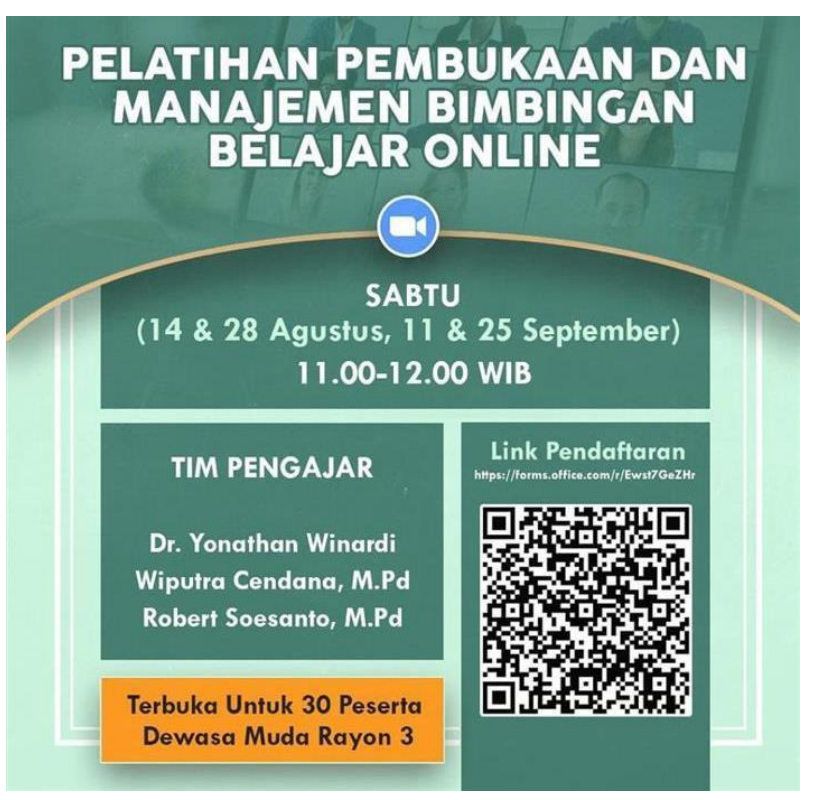

Gambar 1. Flyer Pelatihan

Flyer di atas memiliki komponen-komponen umum seperti nama pelatihan, waktu dan tempat pelatihan, nama-nama pelatih, media pelatihan yaitu Zoom, serta link pendaftaran yang berfungsi sekaligus sebagai media analisa kebutuhan. Selain menanyakan alamat email serta nomor handphone yang aktif, beberapa contoh pertanyaan analisa kebutuhan adalah sebagai berikut

1. Apakah Anda sudah membuka bimbel/memiliki bimbel ?

2. Apakah Anda berencana membuka bimbel online hari-hari ini?

3. Jika Anda sudah membuka bimbel, apakah kendala-kendala dalam manajemen ataupun ketika mengajar/pedagogi ? 
Langkah yang kedua adalah menginformasikan pertemuan tatap muka daring dengan platform Zoom kepada para peserta pelatihan lewat grup Whatsapp yang dibuat. Terdapat 21 peserta yang telah mendaftar dan pertemuan pertama diselenggarakan pada Sabtu, 14 Agustus 2021 pukul 11.00 WIB dengan topik Pedagogi Mengajar Online dan Matematika. Dari hasil analisa kebutuhan, didapati kebutuhan peserta di lapangan adalah khususnya seputar mengajarkan aljabar di bimbel.

Yang ketiga adalah pertemuan tatap muka dengan platform Zoom pada Sabtu, 28 Agustus 2021 dengan tema Manajemen Pembukaan dan Penyelenggaraan Bimbel Online oleh Dr. Yonathan Winardi. Karena semua peserta memiliki iman kristiani, maka disampaikan pula landasan wawasan Kristen alkitabiah mengenai membuka bimbel ataupun mengajar seperti yang terdapat di kitab suci dalam Ulangan 6: 7, Matius 28: 19-20 dan juga Lukas 6: 40. Penyampaian tersebut dipandang baik sehingga memberikan basis dan motivasi intrinsik bagi para peserta bahwa apa yang mereka kerjakan adalah sesuai dengan panggilan dan makna hidup umat kristiani.

Yang keempat adalah pertemuan tatap muka dengan platform Zoom pada Sabtu, 11 September Games dan Sumber-Sumber Belajar Online oleh Wiputra Cendana, M.Pd.

Yang kelima adalah pertemuan tatap muka dengan platform Zoom pada Sabtu, 25 September 2021 Pedagogi Mengajar Bahasa Inggris oleh Dr. Yonathan Winardi. Pertemuan ini akan membahas pendekatan umum dalam mengajar Bahasa Inggris serta teknik-teknis mengajar. Sumber-sumber belajar yang autentik juga disampaikan di sesi pelatihan ini karena hal tersebut merupakan ciri utama pembelajaran Bahasa Inggris yang baik.

Yang terakhir adalah memberikan konsultasi pengembangan kemampuan lewat grup di media sosial. Masing-masing dosen/pengajar akan berinteraksi langsung dengan peserta untuk memastikan, memotivasi, serta memberikan umpan balik. Hal ini dilakukan dengan proaktif 2-3x seminggu dan intensif bilamana ada peserta yang bertanya di grup aplikasi Whatsapp. Di minggu pertama bahkan dibuat dua grup Whatsapp: 1 grup khusus bagi yang sudah membuka bimbel dan 1 grup bagi yang belum membuka bimbel. Hal ini dipandang baik sehingga tanya jawab dapat lebih efisien serta tepat sasaran.

Menjelaskan langkah-langkah sistematis yang dilakukan dalam kegiatan pengabdian masyarakat.

\section{HASIL DAN PEMBAHASAN}

\section{Pembukaan bimbel baru}

Berikut adalah contoh dari bimbel yang telah dibuka dan bimbel baru yang dalam proses pembukaan baru yaitu bimbel pelopor dengan motto 'pelopor siswa-siswi berprestasi' yang berlokasi di Villa Tangerang Elok B1 No.29-33 dengan program bimbel bagi TK, SD, SMP, SMA/SMK, English, dan musik. Bimbel Pelopor ke depannya segera membuka program Bahasa Arab dan Mandarin. Bimbel berikutnya adalah dengan nama bimbel SMALL STARS berlokasi di Vila Regensi Tangerang 2, Permata, Tangerang dengan program Calistung bagi pre-school, TK, PAUD, dan Bahasa Inggris bagi pre-school, TK, SD.

\section{Pemantapan penyelenggaraan bimbel yang sudah berjalan}

Berikut adalah kesaksian dari dua peserta:

1. "Selebihnya mau rancang silabus, beli lisensi mungkin, kerja sama dengan Cambridge curriculum misalnya buat lembaga kursus/sekolah/paud (impian). Doakan semoga tercapai ya Bapak/Ibu. Amin." (FN)

2. "Yang paling berkesan adalah saat membuat visi/misi yang berlandaskan Alkitab lalu bagaimana membuat nama dan motto yang bisa jadi berdampak besar bagi peserta didik yang megikuti bimbel" (G).

Dari dua kesaksian peserta pemilik bimbel di atas, dapat disimpulkan bahwa ada tekad dan inspirasi yang didapatkan oleh peserta yang dapat ditindaklanjuti oleh tim PKM.

\section{Pendampingan pembelajaran anak-anak di rumah}

Berikut adalah sumber-sumber belajar online yang dapat dimanfaatkan untuk mendampingi 
proses pembelajaran anak-anak dari rumah.

Link Algebra-like puzzle:

https://solveme.edc.org/mobiles/\#play

Link Toy Theatre:

https://toytheater.com/pinball/

Link Wordwall:

https://wordwall.net/

Berikut ini adalah beberapa pendapat dari peserta yang mengikuti kegiatan PKM ini, di antaranya dari Ibu rumah tangga yang mendampingi anak-anaknya mengikuti sekolah online dari rumah (Home-based Learning).

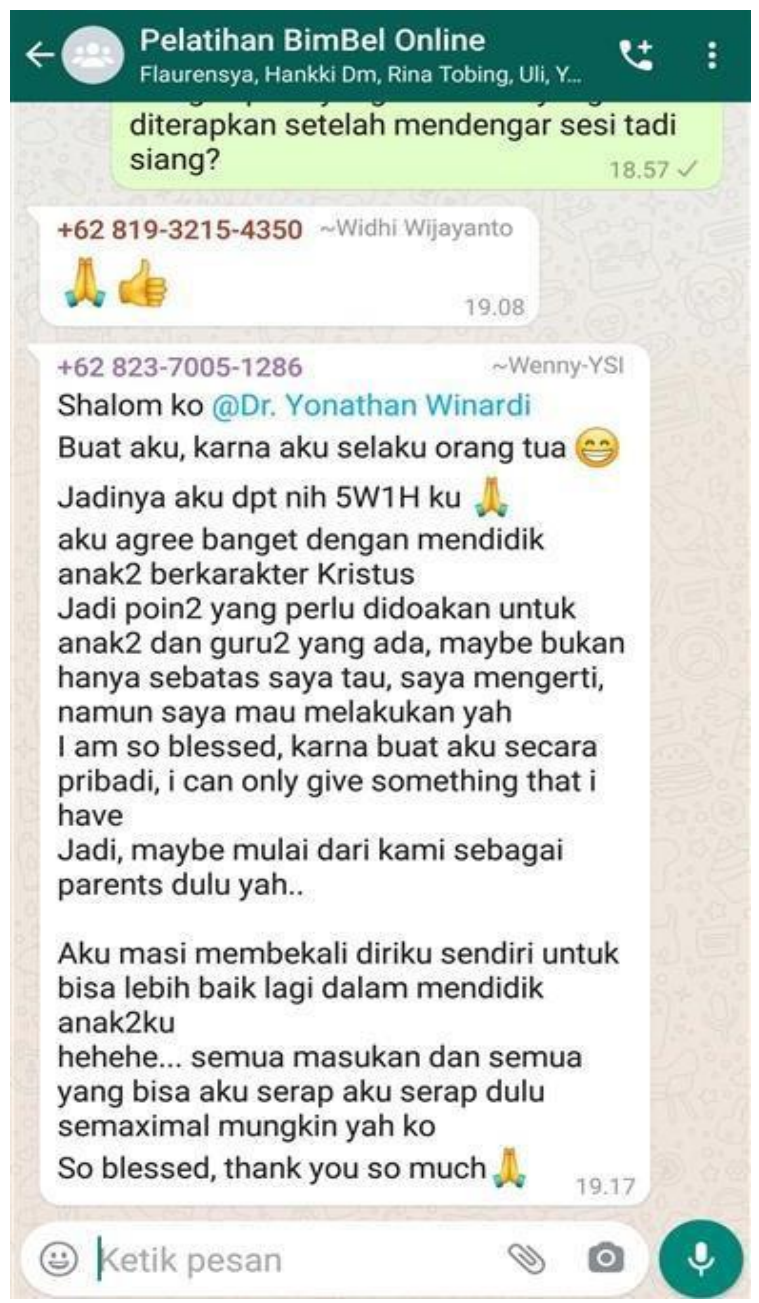

Gambar 2. Kesaksian Peserta Ibu Rumah Tangga
Berikut adalah foto pelatihan yang telah diselenggarakan lewat Zoom

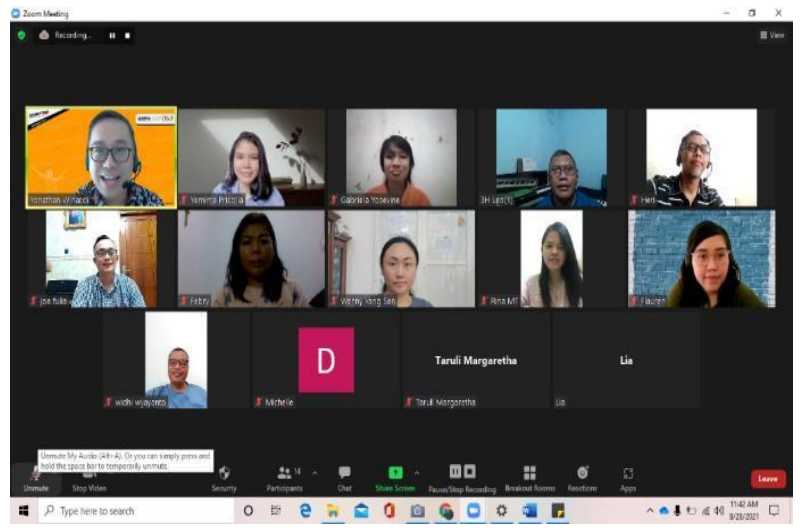

Gambar 3. Foto Pelatihan

\section{Informasi sumber belajar digital dan cetak praktis}

Dalam mengakomodir kebutuhan bimbel secara daring diperlukan rekomendasi sumber belajar digital yang dapat memperlengkapi pembimbingan belajar daring. Peran guru bimbel sebagai gerbang dan jembatan menjadi ilustrasi bagi peserta webinar untuk menyadari potensi dan posisi dari keberadaan guru sebagai fasilitator dan support sistem secara akademis. Kebutuhan anak terhadap pendampingan sangat diperlukan, dan tentunya selama pembelajaran daring, hal ini tergolong minim terjadi. Selain itu, peran guru bimbel sebagai penyemangat dan motivator juga perlu untuk diingat. Kejenuhan yang anak dapatkan ketika belajar di sekolah, setidaknya dapat diatasi melalui peran guru bimbel dalam menguatkan mereka.

Beberapa portal ruang belajar daring dari kemendikbud yang dilengkapi dengan laboratorium maya memberikan makna tersendiri bagi peserta untuk melakukan eksplorasi secara mandiri. Dengan diberikannya beberapa pranala dan ruang untuk menjelajah alhasil hal ini memberikan ruang terbuka untuk mempersiapkan bimbel secara daring. Portal belajar tersebut menekankan pentingnya komunikasi dan kolaborasi dalam sebuah pembelajaran online yang bermakna. 
Kesempatan untuk menggunakan ruang kahoot, quiziz, dan wordwall memberikan kesempatan bagi peserta untuk mengalami pembelajaran daring yang menyenangkan dan menantang. Hal ini memberikan sentuhan baru bagi peserta agar dapat menghadirkan proses bimbingan belajar dengan lebih menarik dan interaktif. Waktu untuk berpikir dalam menyelesaikan pertanyaan-pertanyaan kunci memberikan kesempatan dan pengalaman nyata bagi peserta agar dapat menggunakan kesempatan belajar bermakna sebelum mengajarkan kepada siswa.

Penggunaan Bahasa Inggris dalam beberapa pranala yang diberikan menjadi tantangan tersendiri bagi peserta agar dapat meningkatkan kemampuan Bahasa Inggris yang menjadi modal yang sangat signifikan bagi pembelajar abad ke 21 .

Dalam mendekorasi ruang kelas, pembicara webinar juga memberikan kesempatan peserta untuk membuka sparklebox yang berisi beberapa dekorasi untuk kelas onsite yang dapat membuat sudut ruang kelas lebih menarik. Kesempatan untuk menginventaris kata baru yang dipelajari dan menempelkan pada wordwall dapat menjadi alternatif baru dalam rangka mengingat kata-kata baru yang dipelajari bagi siswa.

Bahkan, pemanfaatan sumber belajar interaktif juga diberikan kepada peserta terkait dengan keperluan pengajaran matematika. Kebanyakan pengajar matematika memiliki kesulitan dalam mendesain media belajar interaktif (Muhazir \& Retnawati, 2020). Oleh karena itu, peserta diberikan penguatan dan beberapa contoh demonstrasi mengenai media pembelajaran interaktif, salah satunya ada wordwall. Hal ini dikarenakan media interaktif tersebut dapat meningkatkan motivasi belajar dari anak-anak (Fitriyani et al., 2020; Rachmavita, 2020). Fitur-fitur yang terdapat di dalamnya memberikan stimulus pada anak untuk terlibat aktif dalam membangun interaksi dan komunikasi serta mereduksi pergumulan ketika belajar matematika (El-ahwal \& Shahin, 2020). Selain itu, peserta diberikan pemahaman bahwa penyajian materi yang dibawakan secara menarik juga dapat membantu dalam mereduksi kecemasan matematis. Dengan adanya penurunan dalam hal kecemasan matematis ini, diharapkan prestasi belajar anak juga turut meningkat. Fakta tersebut sejalan dengan beberapa temuan penelitian yang mendapatkan hasil adanya perbandingan terbalik antara kecemasan matematis dan prestasi matematis anak (Lalian, 2018; Warren et al., 2020).

Terkait dengan guru bimbel dalam bidang seni musik, beberapa alternatif media belajar juga telah diberikan. Dengan didukung beberapa aplikasi yang memiliki nilai guna dalam memainkan alat musik dan prinsip-prinsip nada, hal ini menjadi cara baru untuk belajar di tengah-tengah kondisi daring yang dialami.

\section{Tips Bimbel Online}

Salah satu peserta webinar merupakan orangtua yang memiliki 3 anak menjadi motivasi bagi peserta webinar lainnya. Peran orang tua sebagai pendidik utama tidak boleh dilepaskan dari pilar utama pendidikan. Guru bimbel sebagai pendukung terjadinya pendidikan yang bermakna memiliki peran strategis dalam tumbuh kembangnya naradidik. Kesempatan untuk berkomunikasi secara intensif dan intensional terkait dengan progres anak dari dan ke orangtua sangatlah diperlukan. Pemapar materi telah memberikan alternatif pengiriman progres report kepada orang tua setelah bermain dengan quiziz misalnya.

Mengetahui letak posisi pemahaman siswa dan mau untuk turun sampai ke batas pemahaman siswa menjadi hal utama dalam mendongkrak kebutuhan dan pemahaman siswa agar sampai bersama di tujuan pembelajaran yang dicanangkan. Seringkali, level pemahaman antara guru dan siswa ada dalam gap yang jauh sehingga siswa memiliki kesulitan untuk sampai kepada ekspektasi guru. Guru yang ramah kepada siswa bukanlah teman bagi siswa. Ada batasan yang perlu disadari baik siswa dan guru, sehingga sikap hormat juga tetap terjaga. Guru yang mengajar siswa di kelas atas perlu juga untuk memahami bagaimana berkomunikasi yang efektif kepada siswa-siswi yang diajar. 


\section{KESIMPULAN}

Kegiatan pelatihan manajemen pembukaan dan penyelenggaraan bimbel online telah tuntas diselenggarakan sesuai rencana yaitu $4 \mathrm{x}$ pertemuan pada Sabtu pukul 11.00 di bulan Agustus dan September dengan pendampingan intensif di group media sosial Whatsapp. Pelatihan diberikan dengan mempertimbangkan hasil analisa kebutuhan yang dilakukan di awal melalui kuisioner online yang diisi oleh semua peserta pelatihan. Hasil kegiatan pelatihan dan pendampingan telah memampukan sebagian peserta untuk membuka bimbel baru, menguatkan prinsip dan praktik penyelenggaraan bimbel yang baik, serta memampukan Sebagian peserta mendampingi anak-anak mereka belajar Matematika dan Bahasa Inggris di rumah menggunakan sumber-sumber belajar online yang otentik. Adapun satu hambatan yang ditemukan selama pelaksanaan kegiatan PKM adalah ketika menyampaikan materi mengenai biaya bimbel online untuk dibebankan kepada calon peserta bimbel, mengingat kondisi pandemi yang menyebabkan turunnya pendapat orangtua peserta calon peserta bimbel, sehingga dilema dalam menetapkan biaya bimbel.

Pelatihan ini juga menjadi pembuka jalan bagi kesempatan kegiatan pengabdian kepada masyarakat berikutnya yaitu di kampung Parung Panjang, Bogor sebagai kampung binaan sehingga memungkinkan adanya tindak lanjut serta cakupan yang lebih luas bagi masyarakat yang membutuhkan. Hal ini merupakan salah satu follow-up untuk keberlanjutan kegiatan PKM ini. Proposal PKM untuk tahun 2022 telah rampung dan diajukan ke Lembaga Penelitian dan Pengabdian Masyarakat UPH.

\section{UCAPAN TERIMAKASIH}

Terima kasih kepada Universitas Pelita Harapan yaitu pimpinan Fakultas Ilmu Pendidikan serta Lembaga Penelitian dan Pengabdian kepada Masyarakat (LPPM) dengan No. PkM: PM-045M/FIP/VII/2021 yang telah mendukung terselenggaranya PKM ini dan juga kepada departemen dewasa muda Gereja Bethel Indonesia di Tangerang yang telah memfasilitasi kegiatan pelatihan ini.

\section{REFERENSI}

Abuhammad, S. (2020). Barriers to distance learning during the covid-19 outbreak: A qualitative review from parents' perspective. Heliyon, 6(11), 1-5. https://doi.org/https://doi.org/10.1016/j.heliyo n.2020.e05482

Apsari, R. A., Sripatmi, S., Sariyasa, S., Maulyda, M. A., \& Salsabila, N. H. (2020). Pembelajaran matematika dengan media obrolan kelompok multi-arah sebagai alternatif kelas jarak jauh. Jurnal Elemen, 6(2), 318-332. https://doi.org/10.29408/jel.v6i2.2179

El-ahwal, M. N., \& Shahin, A. (2020). Using videobased on tasks for improving mathematical practice and supporting the productive struggle in learning math among student teachers in the faculty of education. International Journal of Instructional Technology and Educational Studies (IJITES), 1(1), 26-31. https://doi.org/10.21608/ihites.2020.29051.10 13

Fitriyani, Y., Fauzi, I., \& Sari, M. Z. (2020). Motivasi belajar mahasiswa pada pembelajaran daring selama pandemik covid-19. Jurnal Kependidikan: Jurnal Hasil Penelitian Dan Kajian Kepustakaan Di Bidang Pendidikan, Pengajaran Dan Pembelajaran, 7(1), 121-132. https://doi.org/10.23917/ppd.v7i1.10973

Hanifah, N., Isrok'atun, \& Sujana, A. (2018). Melatih Kemampuan Problem Posing. Sumedang: UPI Sumedang Press.

Iftitah, S.L, Anawaty, F.M. (2020). Peran orangtua dalam mendampingi anak di rumah selama pandemi Covid-19. Journal of Childhood Education, Vol. 4(2).

Kerimbayev, N., Nurym, N., Akramova, A., \& Abdykarimova, S. (2020). Virtual educational environment: interactive communication using LMS Moodle. Education and Information Technologies, 25(3), 1965-1982. https://doi.org/10.1007/s10639-019-10067-5

Lalian, O. N. (2018). The effects of using video media in mathematics learning on students' 
cognitive and affective aspects. AIP Conference Proceedings, 1-5. https://doi.org/10.1063/1.5061864

Lock, J.; Eaton, Sarah. E.; and Kessy, E. (2017). Fostering self-regulation in online learning in K-12 education. Northwest Journal of Teacher Education, 12(2).

Manurung, G. N., Manurung, K., Mertosono, S. R., \& Kamaruddin, A. (2020). Perceptions of EFL Learners in the Implementation of Blended Learning Post-natural Disaster at a University in Indonesia. Theory and Practice in Language Studies, 10(8), 959-968. https://doi.org/http://dx.doi.org/10.17507/tpls. 1008.15

Muhazir, A., \& Retnawati, H. (2020). The teachers ' obstacles in implementing technology in mathematics learning classes in the digital era. Journal of Physics: Conference Series, 1511(2020), 1-11. https://doi.org/10.1088/17426596/1511/1/012022

Nazar, Yoenarsih, Yana S, dan Bahtiar Fitanto. (2019). Pengembangan program Pendidikan dan pelatihan. Tangerang Selatan: Universitas Terbuka

Rachmavita, F. P. (2020). Interactive media-based video animation and student learning motivation in mathematics. Journal of Physics: Conference Series, 1663, 1-7. https://doi.org/10.1088/17426596/1663/1/012040

Warren, L., Reilly, D., Herdan, A., \& Lin, Y. (2020). Self-efficacy, performance and the role of blended learning. Journal of Applied Research in Higher Education, 13(1), 98-111. https://doi.org/10.1108/JARHE-08-2019-0210

Yusuf, Adie Erar dan Karantiano Sadasa Putra. (2019). Manajemen strategik dalam pengembangan diklat. Tangerang Selatan: Universitas Terbuka 